\title{
Modification of natural pumice by physical and chemical treatments for removal of zinc ions from aqueous solution
}

\author{
Shinta Indah $^{1 *}$, Denny Helard ${ }^{1}$, Budhi Primasari $^{1}$, Tivany Edwin ${ }^{1}$, and Riyan Hexa Putra ${ }^{1}$ \\ ${ }^{1}$ Department of Environmental Engineering, Universitas Andalas, Padang, Indonesia
}

\begin{abstract}
To increase the adsorption capability of natural pumice from Sungai Pasak, West Sumatra, Indonesia in removal of $\mathrm{Zn}$ from aqueous solution, modification by physical and chemical treatments were evaluated. The treatments were heating at temperatures of $300^{\circ} \mathrm{C}, 450^{\circ} \mathrm{C}$, and $600^{\circ} \mathrm{C}$ for physical and soaking in acid solutions $\left(\mathrm{HCl}, \mathrm{H}_{2} \mathrm{SO}_{4}\right.$, and $\left.\mathrm{HNO}_{3}\right)$ for chemical treatments. The adsorption was performed in batch system with the optimum condition ( 6 of $\mathrm{pH}$ solution, $<63 \mu \mathrm{m}$ of adsorbent diameter, 3 $\mathrm{g} / \mathrm{L}$ of adsorbent dose, $5 \mathrm{mg} / \mathrm{L}$ of $\mathrm{Zn}$ concentration, and $15 \mathrm{~min}$ of contact time). The results revealed that the removal efficiency and $\mathrm{Zn}$ uptake increase using modified pumice from $68.83 \%$ and $1.15 \mathrm{mg} / \mathrm{g}$ to $74.46 \%$ and $1.24 \mathrm{mg} / \mathrm{g}$. The highest removal efficiency and $\mathrm{Zn}$ uptake were obtained from $300^{\circ} \mathrm{C}$ of heating temperatures and $\mathrm{HCl}$ for acid solution. The application of modified adsorbent for removal of $\mathrm{Zn}$ from aqueous solution showed that the modification technique has the potential to increase the removal efficiency and metal uptake of the natural pumice.
\end{abstract}

\section{Introduction}

Zinc is one of necessary trace elements for good health, being involved in a number of essential bodily functions. It is found widely dispersed in nature with some large localized deposits, in groundwater primarily from leaching of geological deposits containing the metals or from contamination due to industrial usage. Zinc is used as the protective coating on galvanized steel and on other metals to prevent corrosion and its salts are used in wood preservatives, like pesticides, like antibiotics, in the manufacture of glazes and glasses, in various cement and glues, as a mordant in dyeing, as a pigment in paints and inks, etc. However, zinc will be high in systems, for instance where the galvanized pipe is connected to copper tubing, because of galvanostatic corrosion [1,2]. For health effects, zinc is relatively nontoxic to man except at extremely high levels or in some salts in which the other components are the main toxic agents. Zinc excess can cause health problems, like stomach cramps, skin irritation, vomiting, nausea, and anemia. WHO has set a maximum limit supply at $5 \mathrm{mg} / \mathrm{l}$ of zinc in drinking water [3].

The increased concern by environmentalist and government on the effect of heavy metals and attempt to safeguard public health brought out to a lot of investigation in the

* Corresponding author: shintaindah@eng.unand.ac.id 
development of advanced technology to remove heavy metals from water and wastewaters. The treatment efforts involved the application of unit processes such as coagulation, chemical precipitation, ion exchange, adsorption, and membrane filtration [4]. Among various treatment technologies, adsorption has been considered as one of the best alternative treatments for water and wastewater treatment due to its high removal efficiency without the production of harmful by-products [4-6]. The investigation for eco-friendly materials for adsorbent with low cost, and with no hazardous by-products generation has been in focus in recent years as an alternative for expensive methods for the removal of pollutants from aqueous solutions. Various approaches have been studied for the development of cheaper and more effective technologies, both to decrease the amount of wastewater produced and to improve the quality of the treated effluent [7].

Geomaterials are low-cost adsorbent resources offering frequent applications to water and wastewater treatments. They are mostly available in the local sources and the requirement for processing them is minimal. Geomaterials such as fired clay [8], bentonite [9], diatomite [10], grey and red clay [11] as well as zeolites [12] were used as adsorbents. In the series of geomaterials, a porous and amorphous material which consists mainly of $\mathrm{SiO}_{2}$ is pumice. Apart from its traditional applications in the construction industry [13], a possible extension with the wide scope was further studied by the researchers in the field of wastewater treatment. The natural and modified pumice were explored to be a better adsorbent for organic and inorganic water pollutants in recent years [14-20].

Various methods have been evaluated for the modification of naturally occurring materials since it is believed that naturally occurring materials have a lower adsorption capacity, and hence appropriate modification will improve natural adsorbent sorption capacity. Generally, modification of the adsorbent exhibits higher adsorption capacities than their unmodified forms due to change in the specific surface area, pore structure, and surface chemical functional groups of the adsorbent. Numerous techniques physically by heat treatment and chemically by using chemicals include mineral and organic acids, bases, oxidizing agent have been used for modification of the adsorbents [14].

The present study focuses on the zinc uptake capacity of natural and modified pumice. Pumice was obtained from Sungai Pasak, West Sumatera, Indonesia. This local mineral is available in a great abundance, a byproduct of the process of sand mining in that area. For this research, the capacities of the natural and physically as well as chemically modified pumice for zinc removal from aqueous solution were evaluated.

\section{Material and methods}

\subsection{Reagents}

All used chemicals in this study were reagent grade from Merck (Germany). Zinc stock solutions were prepared by dissolving of zinc sulfate $\left(\mathrm{ZnSO}_{4} .7 \mathrm{H}_{2} \mathrm{O}\right)$ in distilled water. $\mathrm{HCl}$, $\mathrm{H}_{2} \mathrm{SO}_{4}$, and $\mathrm{HNO}_{3}$ as well as $\mathrm{Al}_{2}\left(\mathrm{SO}_{4}\right)_{3} \cdot 18 \mathrm{H}_{2} \mathrm{O}, \mathrm{Fe}\left(\mathrm{NO}_{3}\right)_{3} .9 \mathrm{H}_{2} \mathrm{O}$, and $\mathrm{MgCl}_{2}$ were used for chemical treatment in the modification of the pumice.

\subsection{Preparation and modification of pumice}

Pumice stone was collected at the riverside of Sungai Pasak, West Sumatera, Indonesia. Si, $\mathrm{Al}$, and $\mathrm{Fe}$ are the major elements in natural pumice from Sungai Pasak, as shown in Table 1 as determined by EDX. Other elements, except $\mathrm{K}, \mathrm{Ca}, \mathrm{Na}$, and $\mathrm{Mg}$ were present in relatively smaller amounts (less than $3 \%$ ). The elemental compositions of the pumice also 
indicate the absence of hazardous or carcinogenic substances. Thus the pumice is considered appropriate as an adsorbent to treat polluted water.

Table 1. Elemental and oxide composition of natural pumice from Sungai Pasak, West Sumatra.

\begin{tabular}{|c|c|}
\hline Element & \% weight \\
\hline $\mathrm{O}$ & 56.38 \\
\hline $\mathrm{Na}$ & 0.49 \\
\hline $\mathrm{Mg}$ & 0.06 \\
\hline $\mathrm{Al}$ & 3.89 \\
\hline $\mathrm{Si}$ & 32.56 \\
\hline $\mathrm{K}$ & 2.41 \\
\hline $\mathrm{Ca}$ & 1.2 \\
\hline $\mathrm{Fe}$ & 3 \\
\hline
\end{tabular}

Prior to use and modify, pumice was washed several times with distilled water to remove any impurities and dried at laboratory temperature $\left(25 \pm 1^{\circ} \mathrm{C}\right)$. Then, the stone was crushed and sieved to produce particle size fractions of $<63 \mu \mathrm{m}$. The obtained particles were prepared for physical and chemical treatments of modification. For physical treatment, pumice was given the heat treatment by burning it at $300^{\circ} \mathrm{C}, 450^{\circ} \mathrm{C}$, and $600^{\circ} \mathrm{C}$ for $3 \mathrm{~h}$. For chemical treatment using an acid solution, pumice was immersed and stirred in $\mathrm{HCl} 1 \mathrm{M}$, $\mathrm{H}_{2} \mathrm{SO}_{4} 1 \mathrm{M}$, and $\mathrm{HNO}_{3} 1 \mathrm{M}$ for $4 \mathrm{~h}$ and washed using distilled water, then dried at $130^{\circ} \mathrm{C}$ for $3 \mathrm{~h}$.

\subsection{Batch adsorption experiments}

Batch adsorption experiment was carried out at laboratory temperature $(25 \pm 1 \mathrm{C}), \mathrm{pH} 6 ; 3$ $\mathrm{g} / \mathrm{L}$ of adsorbent dose $;<63 \mu \mathrm{m}$ of adsorbent diameters and 15 minutes of contact time. The condition of the batch adsorption experiment was obtained from the previous research. In each experiment, $100 \mathrm{~mL}$ of zinc solutions of $5 \mathrm{mg} / \mathrm{L}$ of initial concentration were treated with ten kinds of adsorbents in a set of Erlenmeyer flasks and shaken with a shaker machine at a speed of $100 \mathrm{rpm}$. After 15 minutes of contact time, the adsorbents were separated from the metal solutions by filtered through $0.45 \square \mathrm{m}$ membrane filter. The supernatants were measured for the concentration of total zinc using atomic absorption spectrophotometer (Rayleigh WFX 320, China). The number of zinc ions adsorbed by the pumice was gotten as the difference between the initial and final ion concentrations of the solutions. All experiments were repeated three times and results presented are, consequently, the averaged values of replicate tests.

The removal efficiency and the zinc uptake (qe, $\mathrm{mg} / \mathrm{g}$ ) on natural and modified pumice were calculated by the following mass-balance equation:

$$
\operatorname{Re} \operatorname{moval}(\%)=\frac{C_{0}-C_{e}}{C_{0}} \times 100 \%
$$




$$
q_{e}=\frac{c_{o}-c_{e}}{m} \times V
$$

where $C_{0}$ is the initial concentration of zinc $(\mathrm{mg} / \mathrm{L}), C_{\mathrm{e}}$ is the equilibrium concentration of zinc $(\mathrm{mg} / \mathrm{L}), V$ is the volume of the solution $(\mathrm{L})$, and $m$ is the mass of the pumice $(\mathrm{g})$.

\section{Results and discussion}

\subsection{Physical treatment for modification of pumice}

Fig. 1 shows the removal efficiencies and zinc uptakes of natural pumice and modified pumice by physical treatment. Natural pumice had the removal efficiency of $68.83 \%$, while modified heating pumice at $300^{\circ} \mathrm{C}, 450^{\circ} \mathrm{C}$, and $600^{\circ} \mathrm{C}$ had $73.90 \%, 71.64 \%$, and $63.66 \%$ of removal efficiencies, respectively. The zinc uptake of natural pumice was $1.15 \mathrm{mg} / \mathrm{g}$, whereas by modified heating pumice were $1.23 \mathrm{mg} / \mathrm{g}, 1.19 \mathrm{mg} / \mathrm{g}$, and $1.06 \mathrm{mg} / \mathrm{g}$ for $300^{\circ} \mathrm{C}$, $450^{\circ} \mathrm{C}$, and $600^{\circ} \mathrm{C}$ of heating temperature, respectively. The experimental results showed an increase in the removal efficiency and zinc uptake by using modified pumice by heating at $300^{\circ} \mathrm{C}$ and $450^{\circ} \mathrm{C}$ compared to those of natural pumice.

Physical modification generally results in enhancement of physical characteristics (BET area and total pore volume). The thermal/ heat treatment or calcining process leads to change in the chemical composition of the surface and the porosity of the mineral. The product of heat or thermal processing also showed a significant increase in specific surface area and pore volume [21]. The heat treatment also can remove the water contained in the pores of the adsorbent, so the pores of the adsorbent are empty and may increase its adsorption ability. However, the higher temperature for heat treatment also may cause damage in the absorbent structure which may affect the adsorption process, as obtained from the experiment with $600^{\circ} \mathrm{C}$ of heating temperature. Its removal efficiency and zinc uptake were lower than those of natural pumice.

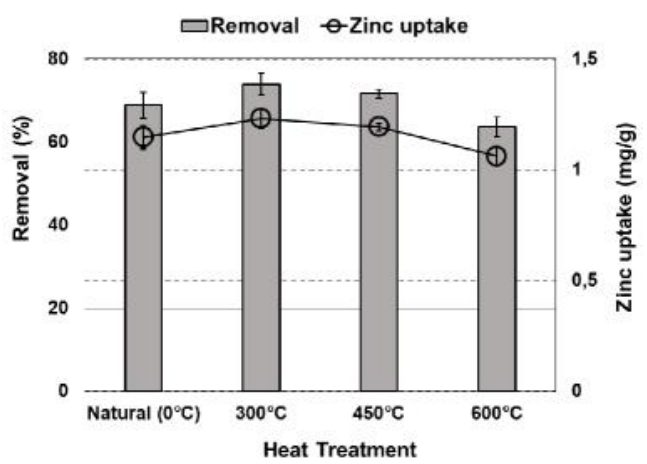

Fig. 1. Removal efficiencies and zinc uptakes of natural and modified pumice by physical treatment.

The SEM analysis results for natural and modified pumice by heat treatment were presented in Fig. 2. It is shown that the natural pumice (Fig. 2a) has a relatively large number of pores, but the pores are covered by other compounds. Meanwhile, modified pumice heated at $300^{\circ} \mathrm{C}$ and $450^{\circ} \mathrm{C}$ are revealed to have a number of open pores (Fig. 2b and $2 \mathrm{c}$ ). These conditions lead to an increase in pore volume and surface area of the adsorbent, thereby increasing the adsorption capacity of the adsorbent. Nevertheless, modified pumice by heating at $600^{\circ} \mathrm{C}$ seem to have fewer pores, may due to damage in the structure of the adsorbent pores caused by overheating temperatures. 

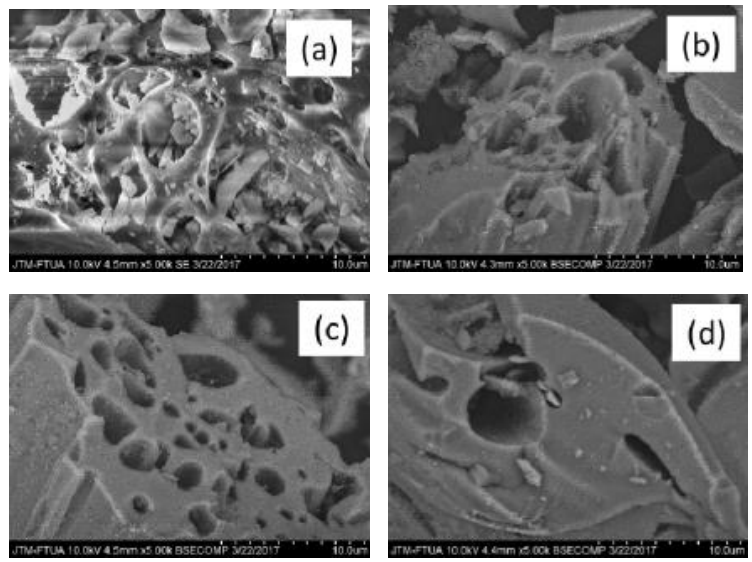

Fig. 2. SEM images of natural pumice (a) and modified pumice by heat treatment at $300^{\circ} \mathrm{C} \mathrm{(b),} \mathrm{(c)}$ $450^{\circ} \mathrm{C}$, and (d) $600^{\circ} \mathrm{C}$.

\subsection{Chemical treatment for modification of pumice}

Based on the experimental results shown in Fig. 3, there was an increase in removal efficiency by using modified pumice with acid immersion compared to the natural pumice. By the natural pumice, the zinc removal efficiency was $68.83 \%$, while with modified pumice by soaking in $\mathrm{HNO}_{3}, \mathrm{HCl}$, and $\mathrm{H}_{2} \mathrm{SO}_{4}$ removal efficiencies reached $72.21 \%$, $74.46 \%$, and $71.92 \%$, respectively. Similar to the removal efficiencies, the zinc uptakes increased as well by using the modified pumice. The zinc uptake of the adsorption using the natural pumice was $1.15 \mathrm{mg} / \mathrm{g}$, increased to $1.20 \mathrm{mg} / \mathrm{g}, 1.24 \mathrm{mg} / \mathrm{g}$ and $1.20 \mathrm{mg} / \mathrm{g}$ using modified pumice by soaking in $\mathrm{HNO}_{3}, \mathrm{HCl}$, and $\mathrm{H}_{2} \mathrm{SO}_{4}$, respectively.

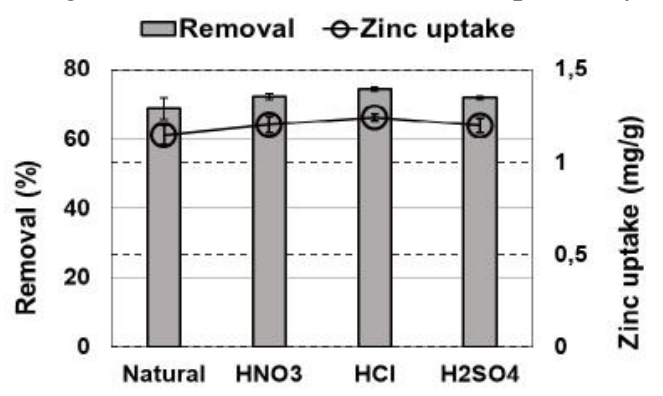

Acid Solution Treatment

Fig. 3. Removal efficiencies and zinc uptakes of natural and modified pumice by chemical treatment.

For the removal of heavy metals from water, acidic functional groups on adsorbent surfaces have been examined and found to be highly favorable because metal ions have a tendency to form metal complexes with the negatively charged acid groups. All of the chemical treatments using oxidizing agents employed for creating acidic functional groups are associated with the reduction of specific surface area and total pore volume, mainly due to the destruction of porous structures within the adsorbent during oxidation. Also, soaking the adsorbent in acid solution may dissolve the impurity compound on the surface of the pores of the adsorbent, increasing surface area, and adsorption capability of adsorbent. Although acid modification decreased the organic content of adsorbent and increased porosity, positively charged surfaces with hydrogen ions prevented to an extra increase of adsorption $[22,23]$. The results show the highest removal efficiency and zinc uptake were 
obtained using modified pumice by soaking in $\mathrm{HCl} 1 \mathrm{M}$. However, compared to $\mathrm{H}_{2} \mathrm{SO}_{4}$ and $\mathrm{HNO}_{3}$ the removal efficiency and zinc uptake were not much different may due to $\mathrm{HCl}$, $\mathrm{H}_{2} \mathrm{SO}_{4}$ and $\mathrm{HNO}_{3}$ are strong acids and the concentrations used for soaking are similar.

As comparison, the increasing in the amount of adsorption per mass unit of the adsorbent ( $\mathrm{qe}, \mathrm{mg} / \mathrm{g}$ ) was also obtained in the adsorption of methylene blue dye from aqueous solutions by modified pumice using $\mathrm{HCl} 1 \mathrm{~N}$. The dye uptakes increased from $1.488 \mathrm{mg} / \mathrm{g}$ by natural pumice to $15.87 \mathrm{mg} / \mathrm{g}$ using the modified pumice [17, 24].

Fig. 4 shows the SEM images of natural and modified pumice by soaking in the acid solution: $\mathrm{HCl}, \mathrm{H}_{2} \mathrm{SO}_{4}$, and $\mathrm{HNO}_{3}$. As mentioned previously, the pores of natural pumice were large in number but were covered by other compounds or impurities (Fig. 4a). The surfaces of modified pumice by acid solution appear to be cleaner, and the pores were uncovered by impurities (Fig. 4a-4c).
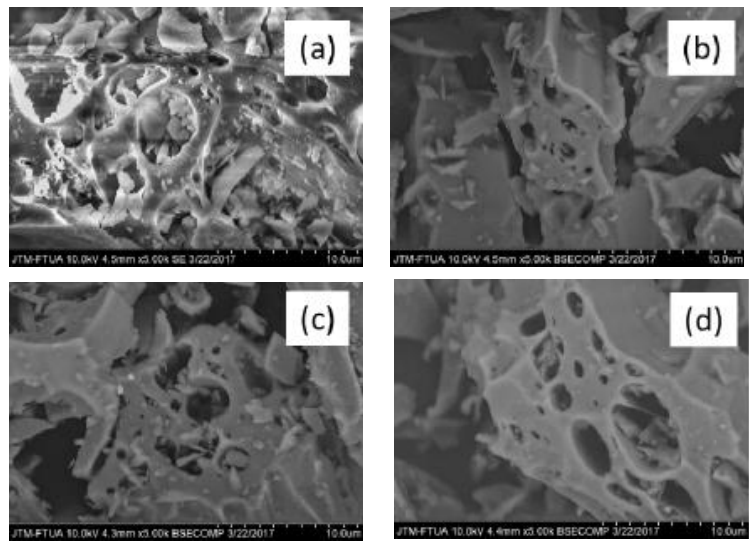

Fig. 4. SEM images of natural pumice (a) and modified pumice by acid solution: $\mathrm{HCl}$ (b), $\mathrm{HNO}_{3}$ (c), and $\mathrm{H}_{2} \mathrm{SO}_{4}(\mathrm{~d})$.

Tabel 2. Comparison of removal efficiencies and zinc uptakes of natural pumice and modified pumice by physical and chemical treatment.

\begin{tabular}{|c|c|c|}
\hline Kind of adsorbent & Removal efficiency (\%) & Zinc Uptake (mg/g) \\
\hline Natural Pumice & 68.83 & 1.15 \\
\hline $\begin{array}{c}\text { Heating at } 300^{\circ} \mathrm{C} \\
\text { (physical treatment) }\end{array}$ & 73.90 & 1.23 \\
\hline $\begin{array}{c}\text { Soaking in } \mathrm{HCl} \mathrm{1M} \\
\text { (chemical treatment) }\end{array}$ & 74.46 & 1.24 \\
\hline
\end{tabular}

Table 2 presents the comparison of removal efficiencies and zinc uptakes of natural pumice and modified pumice by heating at $300^{\circ} \mathrm{C}$ and soaking in $\mathrm{HCl} 1 \mathrm{M}$. These two latest conditions were chosen as the best condition which resulted in the highest removal efficiency and zinc uptake in the batch adsorption experiment. It was revealed that the modification of pumice physically and chemically increased the removal efficiency and zinc uptake. Changes in the surface area, pores and chemical functional groups on the adsorbent surfaces may occur caused by physical and chemical treatment of modification. Finally, it was suggested that to increase the removal efficiency and metal uptake of the pumice, various treatment of modification may be applied. However, further investigations are still needed to explore various treatments and results of the modification of pumice. 


\section{Conclusions}

The removal efficiency and zinc uptake by natural as well as physically and chemically modified pumice from Sungai Pasak, West Sumatra, Indonesia were investigated. The physical modification was performed by heat treatment at $300^{\circ} \mathrm{C}, 450^{\circ} \mathrm{C}$, and $600^{\circ} \mathrm{C}$ and it was found that the highest removal efficiency and zinc uptake were obtained by modified pumice by heating at $300^{\circ} \mathrm{C}$. For chemical modification, three kinds of acid solution were evaluated: $\mathrm{HCl}, \mathrm{H}_{2} \mathrm{SO}_{4}$, and $\mathrm{HNO}_{3}$ with $1 \mathrm{M}$ of concentration. The highest removal efficiency and zinc uptake (74.46\% and $1.24 \mathrm{mg} / \mathrm{g}$ ) were achieved using modified pumice by soaking in $\mathrm{HCl} 1 \mathrm{M}$. Physical and chemical treatment to pumice may modify the surface areas, pore structure, and chemical functional group on the surface of the pumice to increase its adsorption capability. It can be concluded that that pumice from Sungai Pasak is potential as a low-cost adsorbent for $\mathrm{Zn}$ removal from water and wastewater.

This study is funded by Universitas Andalas (Grant No. 45/UN.16.17/PP.PGB/LPPM/2018).

\section{References}

1. E.A. Deliyanni, E.N. Peleka, K.A. Matis, J. Hazard. Mat. 141, 1 (2007)

2. P.C. Mishra, R. K. Patel, J. Hazard. Mater. 168, 1 (2009)

3. WHO, Guidelines for drinking-water quality, 3, 1 (2004)

4. A. Bhatnagar, M. Sillanpaa, Chem. Eng. J. 157, 2-3 (2010)

5. F. Fu, Q. Wang, J. Environ. Man. 92, 3 (2011)

6. A. Bhatnagar, W. Hogland, M. Marques, M. Sillanpaa, Chem. Eng. J. 219 (2013)

7. S. Indah, D. Helard, A. Binuwara, Water Sci. \& Tech. Bonus Issue 2 (2017)

8. S. Babel, T.A. Kurniawan, J. Hazard. Mat. 97, 1-3 (2003)

9. J.J. Liu, X.C. Wang, B. Fan, Bioresour. Technol. 102, 9 (2011)

10. J.H. Xi, M.C. He, C.Y. Lin, Microchem. J. 97, 1 (2011)

11. A. Sari, D. Citak, M. Tuzen, Chem. Eng. J. 162, 2 (2010)

12. P. Chutia, S. Kato, T. Kojima, S. Satokawa, J. Hazard. Mater. 162, 1 (2009)

13. L. Cavaleri, N. Miraglia, M. Papia, Eng. Struct. 25 (2003)

14. A.H. Mahvi, B. Heibati, Res. J. Chem. Env. 16 (2011)

15. M. Malakootian, A. Fatehizadeh, N. Yousefi, Asian J. Chem. 23 (2011)

16. M. Heidar, F. Moattar, S. Nasen, M.T. Samadi, N. Khorasani, Int. J. Env. Res. 5 (2011)

17. F. Akbal, J. Colloid Interface Sci. 286 (2005)

18. M. Kitis, S.S. Kaplan, E. Karakaya, N.O. Yig ${ }^{-i t, ~ G . ~ C i v e l e k o g ~} ` u$, Chemosphere 66 (2007)

19. S. Indah, D. Helard, T. Edwin, R. Pratiwi, AIP Conference Proc. 1823, 020072 (2017)

20. M.N. Sepehr, A. Amrane, K.A. Karimaian, M. Zarrabi, H.R. Ghaffari, J. Taiwan Inst. of Chem. Eng. 45 (2014)

21. G.M. Walker, L. Hansen, J.A. Hanna, S.J. Allen, Water Res. 37 (2003)

22. N.A. Fuadi, A. S. Ibrahem. K.N., N. Ismail, J. App. Sci., 142014 (2014)

23. S. De Gisi, G. Lofrano, M. Grassi, M. Notarnicola, Sust. Mat. and Tech. 9 (2016)

24. Z. Derakhshan, M.A. Baghapour, M. Ranjbar, M. Faramarzian, Health Scope 2, 3 (2013) 